\title{
DIE PREDIKER EN DIE PREDIKING AAN DIE HAND VAN DIE GEGEWENS UIT DIE VRAELYS
}

\section{Doel van prediking}

Die antwoorde op die vraag: Wat beoog $u$ met $u$ prediking? het 'n ryk skakering van antwoorde opgelewer, almal suiwer-Skriftuurlik. Die predikers beoog met die prediking: die stigting en bouing van die gemeente in geloof en godsvrug; verklaring en toepassing van die Woord tot eer van God; eenvoudig-aktuele oopvlekking van die Woord van God tot vermaning en vertroosting; om Jesus Christus as Gekruisigde en Verlosser te verkondig; die hantering van die beloftes en eise van die Genadeverbond; om tot geloof en bekering op te roep in die verkondiging van oordeel en genade.

\section{Tekskeuse}

Wat die tekskeuse betref, volgens 72 predikante wat geantwoord het, kom 62 tot die keuse van 'n teks deur gereelde stelselmatige Bybellees; 53 soek 'n teks in vermoedelik toepaslike gedeeltes n.a.v. die sg. kerklike jaar; 54 vind 'n teks deur die lees van homiletiese werke; 59 deur gesprekke met lidmate; 45 deur beplande Bybellees saam met verklarende aantekeninge; terwyl 70 hulle laat lei deur die pastorale behoeftes van die gemeente.

Waardevolle wenke is ontvang hoe om tot die keuse van 'n teks te kom. 'n Teks kan verkry word deur: na radiopreke of radiooordenkings te luister; die preek of Skrifoordenking van ander te lees; reeksprediking, veral as 'n goeie kommentaar verskyn het; die lees van Bybelse dagboeke; studie van bepaalde teologiese onderwerpe; die bestudering van teologiese tydskrifte; die lees van romans waarin die tydsgees vertolk word; stelselmatige prediking uit elke Bybelboek sodat "minder populêre" dele ook gedek word; eenvoudig 'n hoofstuk te neem en deur eksegese die hoofgedagte te vind; die Kategismus, Nederlandse Geloofsbelydenis en die Dordtse Leerreëls te bestudeer; die lees van homiletiese werke; die nood van krankes, bedroefdes e.a. te probeer peil; bepaalde omstandighede van volk en land wat „skreeu” om die lig van die openbaring; eie ervaringslewe van die week.

Een broeder het gesê hy wag op inspirasie dat 'n teks hom die week moet gryp, maar hy meld ongelukkig nie wat hy doen as 'n teks hom nie gryp nie! Dieselfde broeder gee die wenk dat 'n teksboek aangelê word waarin tekste wat gryp aangeteken kan word.

Slegs een hroeder het laat weet dat hy nie baie moeite met tekste ondervind nie. Met die hulp van 'n eredienskomitee van die kerkraad stel hy 'n preekprogram vir die jaar op.

\section{Die inleiding en slot van die preek}

Die predikers beoog met die inleiding om op pakkende ,aandagprikkelende" manier die tema van die preek aan die orde te stel sonder om die hele "storie" weg te gee. Die oorwoë mening is dat 
die inleiding baie belangrik is, maar dan moet dit kort wees en op die punt af. Gevare wat by die inleiding vermy moet word is: om die hele inhoud van die preek reeds in die begin weg te gee; banale sensasionele inleidings; wydlopige inleidings wat niks met die tema te doen het nie. Een broeder het 'n hekel aan die afgesaagde uitdrukking: „Ons leef vandag in 'n wêreld van ..." en voeg by dat spreke silwer maar swye goud is.

Die rede waarom die inleiding so belangrik is, is omdat die mens van vandag alles kort en saaklik wil hoor. Daarom die weldeurdagte raad: gee in die inleiding dadelik jou grondgedagte en dié moet pakkend, illustratief en tekenend van die teksinhoud wees.

Inleidings waarteen die broeders ernstig beswaar maak is: inleidings wat met 'n storietjie begin om die verteringsproses aan te wakker - dan sit die dood in die pot; inleidings wat so bewustelik "pakkend" gerig word dat selfs die kat uit sy slaap opskrik; puntlose inleiding, sonder 'n punt daarin, sonder 'n punt daaragter; oorgedramatiseerde inleidings - dit misluk omdat die lidmate nugter is en predikante swak voordragkunstenaars is; inleidings soos: "Wie van u ken vir Jerobeam? - Niemand nie, hy het lank voor ons gelewe", inleidings wat te verhewe en kleurvol is - "hef aan" lê nog voor; inleidings wat die weg baan tot kapstokprediking, wat die ervaringslewe van die prediker betrek.

Wat die slot betref, het twee broeders geantwoord dat daar vir hulle nie so iets soos die formele slot van 'n preek bestaan nie. Vir die res is die slot baie belangrik omdat: dit die finale konfrontasie met die hoofgedagte is; die appèl met 'n kerngedagte is; die samevatting met 'n toepassing is; die klimaks is met die opdrag: „Gaan jy en doen net so"; die spyker is wat diep inslaan; die finale konkretisering van die toepassing is; die brug van die preek na die lewe van Maandag is; die na-eggo van die gedagtes is; alle lyne op een punt saamgetrek word, sodat die luisteraar met een sentrale Skrifgedagte huiswaarts mag keer.

Konkluderend kan ons sê dat die meeste broeders saamstem dat die slot die rekapitulasie van die teksinhoud moet wees wat die hoofgedagte weer eens met nadruk tuisbring - maar hulle waarsku ernstig teen 'n slot wat nie tot 'n slotsom kan kom nie. Vermy ook asseblief die baie "ten slotte's" in 'n preek.

\section{Tema en verdeling}

Oor die begrippe tema, hoofgedagtes, sentrale gec'agte is daar 'n Babelse spraakverwarring. Sommige identifiseer tema met hoofgedagte en sentrale gedagte. Vir ander is 'n tema 'n onding" omdat dit tot 'n eksegese lei waarin die prediker 'n teks vir 'n bepaalde, selfgekose onderwerp soek. Een broeder het ruiterlik erken: Ek weet nie, terwyl 'n ander die wysheid kwytgeraak het: „Sien die Homiletiekboek want my persoonlike siening word nie gevra nie. En indien my opinie gevra word, moet ek dit in die Homiletiekboek kry en dit is seker nie die bedoeling nie".

Nadat hy kategories die begrippe tema, hoofgedagte en sen- 
trale gedagte as onsuiwer verwerp het, gee 'n broeder die voorkeur aan die begrip ,grondgedagte". Die grondgedagte word, volgens hom, uit die teks en Skrifverband gesien en uitgelig. Dit gee die eenheid van die preek en gee antwoord op die vraag: Wat wil God in hierdie Skrifgedeelte aan hierdie gemeente sê? Ook oor die begrip „tematiıse preek" het dieselfde vewarring geblyk.

Wat die verdeling van ' $n$ preek betref is daar egter geen verwarring nie. Die verdeling word bepaal deur stof en eksegese, moet organies voortvloei en moet die grondgedagte in sy nuanseringe belig. Iemand stel dit saamvattend baie mooi: ek kom tot 'n verdeling deur myself af te vra hoe ek die hoofgedagte die beste aan die gemeente kan tuisbring.

Die vraag oor enkelvers-prediking, perikoop, homilie, kaleidoskopiese en verrassende prediking het uiteenlopende kommentaar opgelewer. Die meeste gee voorkeur aan enkelverspreiding (27), 12 gee voorkeur aan perikoopprediking, 4 hou van homilieprediking, terwyl die meeste van hulle baie versigtig uitlaat oor kaleidoskopiese en verrassende prediking. Sommige het egter duidelik verklaar dat die teksverband moet aanwys watter „preeksoort" beoefen moet word; dat predikers nie te veel aan een skema moet vashou nie, maar elke onderskeiding met vrug kan gebruik. Indien daar meer as een hoofgedagte in die teks vervat is, is die raad: maak meer as een preek of werk net met een hoofgedagte.

Op die vraag hoe die hoofgedagte beantwoord word, blyk dat die meeste predikers deur bepeinsing van die eksegese tot die formulering van die hoofgedagte kom. Dikwels word 'n tema aan 'n kommentaar of homiletiese werk ontleen. Die hoofgedagte word dan in die gangbare idioom vertolk. Baie min gebruik die tekswoorde as slagspreuk.

Oor die verdeling en sg. „punte” in die preek bestaan uiteenlopende menings. Daar is broeders wat die verdeling as 'n absolute moet propageer met die gedagte: elke ordelike behandeling van 'n saak vereis 'n ordelike indeling. Daar is broeders wat die verdeling as uitgedien beskou omdat die moderne mens nie daarvan hou nie. Die meeste beskou dit as logies en sielkundig nuttig mits dit nie in die teks ingewurg word nie. Daar is meningsverskil of die punteindeling altyd aan die gemeente gegee moet word.

Wat die eise van logika vir die bou van 'n preek betref is almal eensgesind dat dit uiters noodsaaklik is. Indien van punte in die preek gebruik gemaak word, moet dit telkens die hoofgedagte duidelik belig.

Op die vraag of herhaling in die prediking nodig is, het iemand geskryf: Totius het gesê dat dit soms nodig is om by 'n preek te ,,verwyl". Die meeste predikers stem saam dat herhaling nodig is om enkele gedagtes diep te laat inslaan, maar het geen genade vir 'n herhaling wat voortvloei uit swak voorbereiding nie. Een broeder het gevat opgemerk: „M.i. moet 'n preek uitgeskryf word. Herhaling kom meestal voor by die mense wat net met 'n teks en 'n ,gedagte" op die preekstoel gaan. Hy kom haal elke keer by die teks 'n gedagte as hy hom uitput in 'n uitweiding. Die preek lyk dan grafies soos 'n seekat of 'n rol los doringdraad". Onnodige herhaling 
kan vermy word deur jou preek uit te skryf, volledig uit te skryf en te memoriseer.

\section{Explicatio}

Explicatio is vir die meeste nie 'n onderwerp wat hulle uit 'n teks probeer haal nie (dit ruik na kapstokprediking), maar 'n bepaalde teks of Skrifgedeelte wat die prediker wil „oopmaak" om dan 'n bepaalde boodskap te bring. Van elke preek moet geld: So spreek die Here. Daarom beteken explicatio dat die prediker deur eksegese moet deurdring tot die dieper betekenis van 'n teks. Iemand stel dit treffend: Die Woord moet jou oopmaak voor jy dit vir ander kan oopmaak.

Die verhouding van eksegese, openbaringsgeskiedenis, kanoniek en dogmatiek t.o.v. die explicatio is soos volg: Almal is baie noodsaaklik en 'n sine qua non. Eksegese bly die belangrikste arbeidsmetode om die Skrif te verstaan. Openbaringsgeskiedenis dui die groot lyne aan. Kanoniek sorg vir die regte waardering van die plek en agtergrond van die Skrifgedeelte. Dogmatiek is nie die boustene van die eksegese nie maar openbaar wel die logika van die eksegese. Dit werk korrigerend.

Op die vraag: Wat is u mening i.v.m. die leeraspek (didaskein) in die prediking en hoe gaan $u$ te werk om dit in die prediking te verdiskonteer? is die antwoord: Die hele prediking is didaskein, implisiet of eksplisiet. Die leeraspek bly egter gebonde aan die verband van die preek en word streng deur die hoofgedagte van die teks bepaal. Teen dogmatiese prediking moet met alle mag gewaak word.

Die vraag oor die prioriteit tussen explicatio en applicatio is verskillend beantwoord. Omdat eksegese vooraf gaan, het sommige op die vraag "Ja" geantwoord. 'n Broeder wat ,nee" geantwoord het, motiveer sy antwoord dat die prioriteitsgedagte na die $18 \mathrm{e}$ eeuse rasionalisme herlei kan word wat gesê het dat die eksplikasie God se Woord is en die applikasie die prediker s'n. Ander beskou dit as wesentlik ewe belangrik. Dat albei in 'n preek moet wees - daaroor is almal eenstemmig.

Volgens die antwoorde is ' $n$ geslaagde preekverklaring ' $n$ verklaring wat nie slegs op die goeie eksegese berus nie maar ook op ' $n$ biddende bepeinsing daarvan. Dit is geslaagd as die prediker kan deurdring tot die betekenis van die teks in sy verband en as hy dit helder, duidelik en eenvoudig - sonder onnodige studeerkamergeleerdheid - kan oordra.

Die vraag waaraan ' $n$ mens 'n minder geslaagde verklaring van 'n preek kan onderken, het baie reaksie uitgelok. Een broeder het op plastiese wyse hierdie vraag eenvoudig net so beantwoord: Jy kan 'n minder geslaagde verklaring onderken aan...' 'n gapende gemeente! Die predikers vind 'n preek minder geslaagd: as dit gebaseer is op swak eksegese; as dit te veel "sweeping statements" bevat; as verkeerde gevolgtrekkings gemaak word; as die "storie" net oorvertel word en dit word dan eksegese genoem; as dit 'n geskarrel 
en langdradige detail bevat wat nie relevant is nie; as dit eksemplariese prediking is; as dit kapstokprediking en sedeprediking is; as dit 'n lang toepassing bevat oor allerlei sondes; as dit „onoortuigend modderig" is.

Die broeders wys verder daarop dat 'n preek nie kan slaag as nie genoeg gebid word om die verligting van Gods Heilige Gees nie; as daar nie genoeg kontak is met die probleme en eise van die moderne mens nie; as 'n preek lidmate, wat goed onderlê is in die Skrif, onrustig mak omdat hulle vra: maar wat wou die man nou eintlik gesê het?

\section{Die applicatio}

Die applicatio word as baie belangrik beskou. Daarsonder is die preek 'n bietjie teologiese gimnastiek waarin die persoonlike sprake van God latent bly. Dit moet die indikatief van die verklaring transformeer tot die imperatief van geloofsaktiwiteit.

Die vraag hoe die toepassing verkry word het 'n variasie van metodes na vore gebring. Baie predikers soek doelbewus na stof om 'n sekere lig op 'n bepaalde probleem te werp (22), maar die meeste (38) verklaar die teks en laat dan die toepassing uit die eksegese gebore word, soos iemand dit stel: „Ek as bedienaar moet nie toepassings maak nie. As ek die Skrif reg verklaar, is die toepassing meteens gegee. Ek moet 'n kanaal wees vir die deurvloeiing van die Skrifboodskap". Dan is daar ook baie wat hulle in hulle toepassings laat lei deur homiletiese werke (,,my eie gedagtes is tog te arm en gebrekkig"), deur preke van ander te lees, deur pastorale behoeftes.

As 'n broeder kla: „Ek worstel om die Skrif in die omstandighede van vandag aan die mens toe te pas", kom 'n ander met die troos: ,'n Mens ontwikkel algaande 'n aanvoeling vir die toepassing".

Op die vraag of 'n prediker sy toepassing by die smaak van die gemeente moet aanpas, is die antwoord baie duidelik van die meeste broeders: Nooit by die smaak nie maar wel by die behoeftes. Die sout van Gods Woord moet in die toepassing maar brand in die wonde, maar aan die ander kant is dit baie belangrik hoe 'n prediker die toepassing bring.

'n Prediker ontstig in sy toepassing wanneer hy iemand van die preekstoef afransel omdat hy nie die moed het om met die persoon onder vier oë te praat nie; bombastiese veroordelende uit-die-hoogtetoepassing; die gemeente nie met God konfronteer nie maar met ds. X; die gemeente met persoonlike sondelysies konfronteer en nie met Evangeliese liefde nie; net slae uitdeel of net gerus stel; die preekstoel as 'n uitlaatklep vir frustrasie gebruik. 'n Goeie wenk vir elke prediker is: as die Evangelie ontstig is dit goed, maar as die dominee ontstig is dit nie goed nie.

Ek het gesê dat die meeste broeders gesê het jy moet nie by die smaak van die gemeente aanpas nie. Tog is daar 'n paar antwoorde wat my ontstel het. Ek wil dit vir u lees: Een broeder het gesê: ,,as 'n toepassing ontstigtelik kan wees, moet dit liefs vermy word". 'n Ander sê: „,die toepassing hang af van die gesindheid 
van die gemeente op die stadium". 'n Ander: „daar is 'n toepassing wat beter met huisbesoek gedoen kan word". Iemand anders sê: „Vermy om onnodige skuldgevoel op te wek". 'n Ander: jou toepassing hang af van die vertrouensband tussen predikant en gemeente". Nog iemand sê: „ek sal sekere aanpassings maak as dit slegs enkele lidmate raak". En dan sê nog 'n broeder: „Jy moet nie aanstoot deur jou toepassing gee nie - en dan verwys hy na Paulus wat selfs nie wil vleis eet as dit aanstoot gee nie".

Hierdie paar antwoorde stem my onrustig. Daarom wil ek met nadruk beklemtoon: Nooit mag ' $n$ toepassing by die smaak van die gemeente aanpas nie. 'n Prediker moet waak dat hy nie 'n valse profeet word nie. As ek die geskiedenis lees van die ongehoorsame profeet en ou profeet van Betel (1 Kon. 13), dan is ek so bevrees dat ek in my prediking my so kan aanpas dat ek ook vals word in die oë van die Here (veral ook met die oog op ons intervolkere- en intermenslike verhoudings in Suid-Afrika).

Wat die gerigtheid van die prediking op die gemeente betref t.o.v. eenheid en differensiasie, is die algemene gedagte dat die Skrif die hele gemeente tref en nie differensieer nie. Die prediker moet maar net God se openbaring bring en almal sal gestig word. Daar moet gewaak word teen meganiese opsplitsing van 'n gemeente omdat kinders net sulke goeie beoordelaars is as volwassenes. Die goue reël is: berei jou voor soos 'n teoloog en rig jou preek op die tienjariges.

Die vraag oor die „eietydse" van die mens en wêreld van vandag het soveel variërende gedagtes ontlok, dat dit vir my duidelik is dat ons nie weet wat die eietydse van die mens en wêreld van vandag is nie. Ons sal hierdie saak baie deeglik moet bespreek, want as die predikant nie die leefwêreld van die lidmate bereik nie, as hy nie weet wie hy voor hom het nie - kan hy waarlik nie die Woord van God met seën aan die gemeente bring nie.

Die predikante voel, weliswaar, hierdie leemte baie sterk aan. Om die "eietydse" van die mens te begryp lees hulle tydskrifte en kerklike blaaie, woon lesings en konferensies by, maak gebruik van nuusmedia, neem aan sport en kultuurbedrywighede deel om die mense te leer ken; gesels met persone van verskillende leeftye; doen intensief huisbesoek en besoek selfs die werksplekke van sommige lidmate. Desnieteenstaande beken 'n broeder: "vir my bly dit 'n probleem".

Ook in die prediking probeer die prediker pastoraal saamleef met die gemeente deur hom met sy boodskap te identifiseer; deur ook vir homself te preek; deur vir die lidmate te sê: bid saam met my, luister saam met my; deur "ons" te sê en nie „u" en ,ek" nie; deur liefde en begrip aan die dag te lê en met bewoënheid te preek.

Die vraag oor die moderne gedagtes t.o.v. aktueler prediking het sterk kommentaar uitgelok. Sommige broeders het die woord ,aktueel" sterk aangeval. Hulle sê Gods Woord bly altyd aktueel en kan nie deur die mens aktueel gemaak word nie. Die vraag na die dialogiese metode (m.a.w. dat die prediker in sy preek vrae stel wat leef in die harte van die hoorders) het meer waardering gevind mits die antwoord daarop onmiddellik in die prediking gebied word. 
Op die sendingveld is die vraag in die prediking baie waardevol. Broeders het daarop gewys dat Jesus se prediking dialogies is, maar só dat God se sprake die eerste en finale bly. Dialogiese prediking kan met reserwe toegepas word.

Die vraag of soekende prediking geoorloof is, het woede ontlok. Die kommentaar op soekende prediking is: „Twak; ek het daar geen ooghare voor nie". Soekende prediking is gevaarlik - eksistensialisties. Die mens is van nature 'n soeker en moet nie nog in die preek daartoe aangemoedig word nie. Die prediking mag nooit soekend wees nie omdat Christus, die Waarheid, ons opgesoek het. Die prediker moet soekend wees voor hy sy preek maak, nie in die preek nie.

Jeuggerigte prediking is belangrik in dié sin dat elke preek jeuggerig moet wees. Diskussie na die diens oor die preek is goed hoewel dit ook nadelig kan wees as die preek gelikwideer word. Een broeder sê dit klink teoreties mooi maar werk prakties nie. Bybelstudie i.p.v. prediking is uit die Bose.

Op die vraag hoe die indikatief van die genade, die imperatief van die dankbaarheid en die bevindelike in die toepassing tot sy reg kom, is die antwoord oor die algemeen: deur Christus en sy soenverdienste op die voorgrond te stel. As jy die toesegging en eis van die genadeverbond reg bring, sal jou preek bevindelik wees.

\section{Wat die formele betref:}

Die prediker moet in die alledaagse omgangstaal preek. Wees in jou preektaal kinderlik maar nie kinderagtig met die „slang" van die hippie nie. Kommunikasie kan verbreek word as die taal van die hoorder nie gepraat word nie. Preek eenvoudig, lewendig, in kort sinne. Konkrete werkwoorde is baie effektief. Vermy die Okke Jager-styl omdat dit oneg is en die element van vermaak bevat. Lees goeie digbundels en goeie prosa om jou taal te verbeter.

Die vraag t.o.v. preke sonder of met skets, preke wat volledig uitgeskryf is het baie kommentaar uitgelok. Preke sonder skets word sonder uitsondering veroordeel. „Dit sal my en my gemeente gedaan maak", sê iemand. En 'n ander: "99 persent predikante - waaronder ek - moet dit soos pes vermy". 48 predikante verkies dat die preek volledig uitgeskryf moet word, maar dan moet dit baie goed gememoriseer word. Die preek moet in die kop wees en nie die kop in die preek nie. Die res verkies sketse, maar dan gewoonlik eers nadat die preek voluit neergeskryf is. Iemand het voorgestel dat jy slegs aan die een kant van die preekboek skryf terwyl jy aan die ander kant 'n opsomming maak.

Probleme wat predikers moet oorkom om te kan preek is: onmag om in die prediking soos 'n vader met 'n kind te praat; periodieke insinking in geloofslewe, gebrek aan vermoë om die dinge waaroor ek preek in my lewe waar te maak; om te begin en na te lees; bekwaamheid; om Woord suiwer te bring; om die Skrif te laat spreek en nie jou eie gedagtes nie; geestelike luiheid, gebrek aan inspirasie en sleur; oppervlakkige Skrifstudie; gebrek aan tyd vir meditasie oor preek; om te veel ander se gedagtes in die preek oor 
te neem; vooroordeel teen sekere lidmate; moeilik om altyd objektief te wees; moedeloosheid; angs dat jy nie in die preek sal slaag nie; baie genade nodig as iemand jou prys, maar as hy jou kritiseer nog meer genade nodig; om nie in piëtisme te verval nie; dat dit nie om my gaan nie maar om die Woord; eie nietigheid teenoor geweldige roeping; ,ek worstel nie met my inwendige roeping nie maar met my uitwendige roeping"; onsekerheid waaroor ek moet preek; 'n mens moet deur die Heilige Gees gelei word om die atmosfeer van die erediens aan te voel en te skep.

Die predikers evalueer hulle prediking deur met kerkraadslede te praat wat ryp in ervaring is; deur met hulle vrouens te praat en deur bandopnemers.

Wat die twee preke per week betref is daar 17 wat nie twee per week maak nie - preek ou Kategismuspreke. 21 maak nuwe preke, al skryf sommige net 'n oue oor. Een broeder het gesê: „Sopas in 'n nuwe gemeente gekom - heelwat vars preke..." Wat herhaling van 'n ,ou" preek betref, is daar oor die algemeen nie beswaar nie mits dit opnuut verwerk word. Een broeder het gesê dat dit beter is in ' $n$ noodsituasie om 'n behoorlik deurdagte ou preek te preek as 'n nuwe wat halfklaar is.

\section{Wenke met preekwerk}

Hier volg waardevolle wenke van broeders predikante:

$\square$ Moenie die woord „kerkbesoek" te veel in 'n preek gebruik nie. Preek bekering dan kom bydraes en kerkbesoek vanself reg. Handel die voorbereiding van jou preke so vroeg moontlik in die week af.

$\square$ Soms maak ek met die minste boek die bes geslaagde preek. Jy vertrou te veel op kommentare.

Vermanende preke wat 'n platvloerse uitvreet en brutale geselskarakter het, het baie min krag. Vermaning moet gedra word deur die liefdesbeginsel.

$\square \quad$ Huisbesoek en gesprekke stimuleer baie. Lees ander preke ook. Ken jou Bybel en jou mense en jou tyd en jouself - en jou God.

$\square \quad$ Praat met die gemeente, moenie oor hulle koppe vir die orrelpype preek nie. Moenie sing soos 'n brommer teen 'n toe venster nie.

Tematiese prediking spaar baie tekssoekwerk, bv. preke oor gelykenisse, 'n reeks preke oor 'n bepaalde boek, ens.

$\square$ Preekwerk is geloofswerk en sonder biddende worsteling om lig is die moeite tevergeefs.

Ek het gevind dat konsentrasie om die taal te vereenvoudig, die inhoud te filtreer, konsentreer en groepeer, selfs wanneer die preek klaar uitgeskryf is en instudeer word, die kommunikasie bevorder. Probeer dat die preek sover moontlik beantwoord aan: konsentrasie op hoofgedagte; kontras in die fasette; plastiek in die uitbeelding.

As jy die teks gekry het, lees dit oor en oor en broei daarop. Hoe duideliker ek vir myself uitgemaak het presies wat die Here in hierdie Skrifgedeelte vir die kerk en wêreld vandag 
wil sê, hoe meer vrug is daar op die prediking.

$\square$ 'n Goeie preek vereis nie net daaglikse studie nie, maar veral ook bepeinsing, besinning en betragting.

$\square \quad$ As jy jou preek nie kan deursien nie, gaan slaap met die probleem - môre kom dit meestal reg. (Hierdie predikant noem dit die ,inkubasie"-metode.)

$\square$ Begin vroegtydig. Gebruik alle beskikbaar tyd om te dink en te lees.

$\square \quad$ Noodsaaklik om baie en wyd te lees.

$\square$ 'n Mens moet net so 'n goeie kenner wees van die kulturele wêreld waarin ons lewe en van wat in harte van mense lewe, as van die Bybel. Prediking bly die Woord van God deur die prediker tot mense.

$\square$ Te veel tyd van die predikant word deur nie noodsaaklike dinge in beslag geneem.

$\square$ Hou 'n papier en potlood byderhand. Gedagtes oor die preek skiet jou soms agter die stuur van jou motor te binne. Sonder gebed is preekmaak nie moontlik nie. Vra soms 'n vertroude vriend of jou vrou wat 'n goeie toepassing sal wees. Dis verbasend om te sien hoe die gemeente soms kan toepas.

$\square$ Ywerige studie en meelewing met lidmate onontbeerlik.

$\square$ Bybelse dagboeke en dagboeke oor Kategismus is baie waardevol om gedagtegang te prikkel.

$\square \quad$ Daar is 'n groot tekort aan werklik suiwer eksegetiese en homiletiese werke.

$\square \quad$ Ek bepleit dit dat ons preke asb. voluit sal uitskrywe.

$\square$ Moenie vooraf bepaal hoe lank jou preek moet wees nie. As jy dit in 3 minute kan sê, is 10 minute te lank.

$\square$ Die lees van baie preke en homiletiese werke help baie.

$\square$ Wees natuurlik, eerlik, nie outoritêr nie - emosionele aanslag (nie opsweep nie) is geslaagd.

$\square \quad$ Reeksprediking het baie voordele. Die probleem bly nog steeds die volheid van die Christusprediking by preke.

$\square$ Dit het keer op keer gebeur dat mense 'n preek goed vind waarvan ekself min dink en andersom. Gevolgtrekking: die deurkom van ' $n$ preek is ten diepste 'n Geestesgebeurtenis.

$\square$ Die meeste mense se konsentrasievermoë neem skerp af na 20 minute. 'n Afgerolde skets voor en soms ná die erediens is nuttig.

$\square$ Soek jou teks so vroeg moontlik en loop met hom rond tot hy ryp word. Dan is dit aktueel.

$\square$ Verdiep jou in die Skrif.

$\square$ Moenie soos iemand anders probeer preek nie, wees jouself. Moenie mooi en aangrypende preke probeer maak nie - die Woord self is mooi en aangrypend.

$\square$ Om vas te stel of jy die volle raad van God verkondig, maak 'n indeks van die tekste waaruit jy al gepreek het. Dan sal jy merk uit welke Boeke jy nog nie gepreek het nie.

$\square$ Die mees aktuele prediking is Skrifprediking.

口 Die gawe, maar ook eis van die genadeverbond moet in elke 
preek helder gestel word. Ons moet oproep tot bekering, nooit aan die slaap sus nie.

$\square$ Bly op hoogte met toestande in die gemeente, in jou land en in die wêreld.

$\square$ Die preek moet deel van jou word en nie 'n opstel wees nie.

$\square$ Ons predikante kla te veel hoe moeilik dit is om preek te maak. As ons net ons plig doen, ook op ons knieë, dan het ons geen probleme nie.

$\square$ Gee ons nie miskien te min aandag aan die kinders in ons preke nie? Dit is nie genoeg om „kinders" by te voeg by ons „broeders en susters" nie. Myns insiens gee die inhoud van ons preke blyke van ' $n$ gebrek aan belangstelling in ons kinders.

- Moenie dink preekmaak is 'n bitter swaar werk nie. Dit frustreer. As jy nie swaarkry nie, kry jou gemeente swaar, maar dis lekker swaarkry. Worstel met jou eksegese tot jy jou grondgedagte raakgevat het. Moenie jou preek halfgaar opdis nie. Preek met groot vrymoedigheid (Hand. $4: 29$ en 31).

$\square$ Dit is 'n groot voorreg om steeds met die lewende Woord te doen te kry.

'n Baie diep dankbaarheid vloei uit die hart vir die genade dat God aan ons die Koninklike, profetiese taak geskenk het om medewerkers in sy wingerd te wees.

C. J. Malan. 